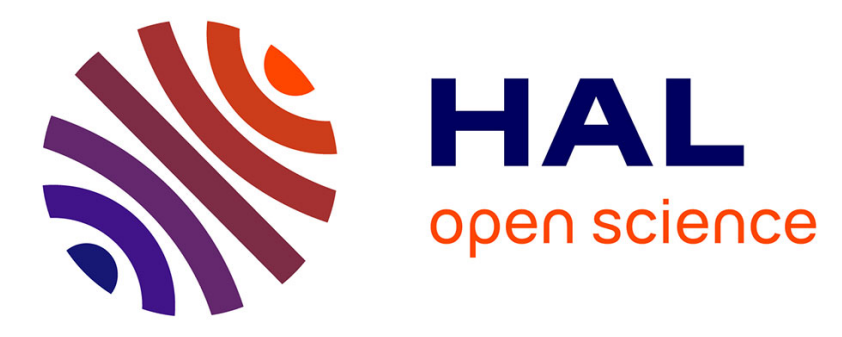

\title{
High-density $\mathrm{O}+$ in Earth's outer magnetosphere and its effect on dayside magnetopause magnetic reconnection
}

\author{
S. Fuselier, J. Mukherjee, M. Denton, S. Petrinec, K. Trattner, S. \\ Toledo-redondo, M. André, N. Aunai, C. Chappell, A. Glocer, et al.
}

\section{To cite this version:}

S. Fuselier, J. Mukherjee, M. Denton, S. Petrinec, K. Trattner, et al.. High-density O + in Earth's outer magnetosphere and its effect on dayside magnetopause magnetic reconnection. Journal of Geophysical Research Space Physics, 2019, 124 (12), pp.10257-10269. 10.1029/2019JA027396 • hal-03321018

\section{HAL Id: hal-03321018 https://hal.science/hal-03321018}

Submitted on 1 Dec 2021

HAL is a multi-disciplinary open access archive for the deposit and dissemination of scientific research documents, whether they are published or not. The documents may come from teaching and research institutions in France or abroad, or from public or private research centers.
L'archive ouverte pluridisciplinaire HAL, est destinée au dépôt et à la diffusion de documents scientifiques de niveau recherche, publiés ou non, émanant des établissements d'enseignement et de recherche français ou étrangers, des laboratoires publics ou privés. 


\section{JGR Space Physics}

\section{RESEARCH ARTICLE \\ 10.1029/2019JA027396 \\ Key Points: \\ - The magnetospheric warm plasma cloak is $\mathrm{O}^{+}$-rich during geomagnetically active times \\ - The warm plasma cloak reduces the magnetic reconnection rate at the magnetopause $\sim 2-4 \%$ of the time \\ - During geomagnetic storms, the $\mathrm{O}^{+}$-rich warm plasma cloak reduces the reconnection rate by $>20 \%$ sometime during $25 \%$ of the storms}

Correspondence to:

S. A. Fuselier,

stephen.fuselier@swri.org

Citation:

Fuselier, S. A., Mukherjee, J., Denton, M. H., Petrinec, S. M., Trattner, K. J. Toledo-Redondo, S., et al. (2019). High-density $\mathrm{O}^{+}$in Earth's outer magnetosphere and its effect on dayside magnetopause magnetic reconnection. Journal of Geophysical Research: Space Physics, 124, 10,257-10,269. https:// doi.org/10.1029/2019JA027396

Received 11 SEP 2019 Accepted 25 NOV 2019 Accepted article online 15 DEC 2019 Published online 26 DEC 2019

\section{High-density $\mathrm{O}^{+}$in Earth's outer magnetosphere and its effect on dayside magnetopause magnetic reconnection}

S. A. Fuselier ${ }^{1,2}$, J. Mukherjee ${ }^{1}$, M. H. Denton ${ }^{3}$, S. M. Petrinec ${ }^{4}$, K. J. Trattner ${ }^{5}$, S. Toledo-Redondo ${ }^{6}$, M. André ${ }^{7}$, N. Aunai ${ }^{8}$, C. R. Chappell ${ }^{9}$, A. Glocer $^{10}$, S. Haaland ${ }^{11}$, M. Hesse ${ }^{12}$, L. M. Kistler ${ }^{13}$,

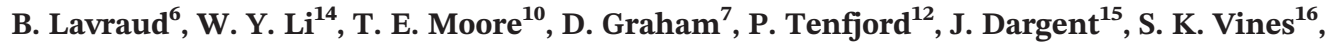
R. J. Strangeway ${ }^{17}$, and J. L. Burch ${ }^{1}$

${ }^{1}$ Southwest Research Institute, San Antonio, TX, USA, ${ }^{2}$ Department of Physics and Astronomy, University of Texas at San Antonio, San Antonio, TX, USA, ${ }^{3}$ New Mexico Consortium, Los Alamos, NM, USA, ${ }^{4}$ Lockheed Martin Advanced Technology Center, Palo Alto, CA, USA, ${ }^{5}$ Laboratory for Atmospheric and Space Physics, University of Colorado Boulder, Boulder, CO, USA, ${ }^{6}$ Institut de Recherche en Astrophysique et Planétologie, Université de Toulouse, CNRS, UPS, CNES, Toulouse, France, ${ }^{7}$ Swedish Institute of Space Physics, Uppsala, Sweden, ${ }^{8}$ Laboratoire de Physique des Plasmas, France, ${ }^{9}$ Vanderbilt University, USA, ${ }^{10}$ NASA Goddard Space Flight Center, Greenbelt, MD, USA, ${ }^{11}$ Max Planck Institute, Germany, ${ }^{12}$ University of Bergen, Bergen, Norway, ${ }^{13}$ University of New Hampshire, Durham, NH, USA, ${ }^{14}$ State Key Laboratory of Space Weather, National Space Science Center, China, ${ }^{15}$ Physics Department E. Fermi University of Pisa, Pisa, Italy, ${ }^{16}$ Applied Physics Laboratory, Johns Hopkins University, Laurel, MD, USA, ${ }^{17}$ Earth and Space Sciences, University of California, Los Angeles, CA, USA

Abstract The warm plasma cloak is a source of magnetospheric plasma that contain significant $\mathrm{O}^{+}$. When the $\mathrm{O}^{+}$density in the magnetosphere near the magnetopause is $>0.2 \mathrm{~cm}^{-3}$ and the $\mathrm{H}^{+}$density is $<1.5 \mathrm{~cm}^{-3}$, then $\mathrm{O}^{+}$dominates the magnetospheric ion mass density by more than a factor of 2 . A survey is conducted of such $\mathrm{O}^{+}$-rich warm plasma cloak intervals and their effect on reconnection at the Earth's magnetopause. The survey uses data from the Magnetospheric Multiscale mission (MMS) and the results are compared and combined with a previous survey of the warm plasma cloak. Overall, the warm plasma cloak and the $\mathrm{O}^{+}$-rich warm plasma cloak reduce the magnetopause reconnection rate by $>20 \%$ due to mass-loading only about $2 \%$ to $4 \%$ of the time. However, during geomagnetic storms, $\mathrm{O}^{+}$ dominates the mass density of the warm plasma cloak and these mass densities are very high. Therefore, a separate study is conducted to determine the effect of the warm plasma cloak on magnetopause reconnection during geomagnetically disturbed times. This study shows that the warm plasma cloak reduces the reconnection rate significantly about $25 \%$ of the time during disturbed conditions.

\section{Introduction}

In the original formulation of the interaction between the solar wind and the Earth's magnetosphere (Chapman \& Ferraro, 1931), an unmagnetized solar wind plasma interacts with a plasma-less terrestrial magnetic field. Two important modifications to this interaction were the realization that the solar wind contains a magnetic field frozen into the plasma and that the Earth's magnetosphere contains plasma. Because the magnetosheath magnetic field is frozen into the shocked solar wind plasma, processes that transfer plasma across the magnetopause must break this frozen-in condition. The dominant plasma transfer process at the magnetopause that achieves this break is magnetic reconnection. However, the presence of magnetospheric plasma affects reconnection at the boundary.

Magnetospheric plasma in the dayside, outer magnetosphere near the magnetopause (i.e., L-shells >7-8) is multi-species, variable, and has three sources. The first source, from the magnetotail, is the ring current. The ion ring current plasma at the dayside magnetopause originates from the solar wind and ionosphere and has relatively high energy ( $10^{\prime}$ s of $\mathrm{keV}$ ). The ring current density varies with magnetospheric activity and this source consists of $\mathrm{H}^{+}$and $\mathrm{He}^{2+}$ of solar wind origin and $\mathrm{H}^{+}, \mathrm{He}^{+}$, and $\mathrm{O}^{+}$of ionospheric origin (e.g., Kistler et al., 1989). The density of this source is usually low enough that it is combined with the other two sources when the effects of magnetospheric plasma on magnetopause reconnection are considered (e.g., Fuselier et al., 2017).

The second source, from the duskside/dayside close to the Earth (i.e., L-shells $<7$ ), is the plasmaspheric drainage plume. This low-energy $(\sim 1 \mathrm{eV})$ plasmaspheric plasma propagates to the dayside/duskside
(C)2019. American Geophysical Union. All Rights Reserved. 
magnetopause when convection is enhanced (e.g., Goldstein et al., 2004). It consists primarily of $\mathrm{H}^{+}$and $\mathrm{He}^{+}$ with a lower concentration of $\mathrm{O}^{+}$(e.g., Fuselier et al., 2017), all of ionospheric origin.

The third source, from the high-latitude ionosphere, is the warm plasma cloak (e.g., Chappell et al., 2008). This moderate energy ( 10 's of eV to several keV) plasma is enhanced in the dayside magnetosphere when geomagnetic activity is high and consists primarily of $\mathrm{H}^{+}$and $\mathrm{O}^{+}$with a lower concentration of $\mathrm{He}^{+}$(e.g., Fuselier et al. (2017)). The ions in the cloak may originate in the high-latitude, nightside ionosphere and convect to the dayside (Chappell et al., 2008) or may originate in the dayside high-latitude ionosphere and populate the inner magnetosphere (Gkioulidou et al., 2019) or the low-latitude boundary layer (Fuselier et al., 2019). During periods of high geomagnetic activity, the $\mathrm{O}^{+}$flux dominates the ion outflow from the high-latitude ionosphere (Yau et al., 1984) and therefore may dominate the warm plasma cloak.

These three magnetospheric plasma components affect magnetopause reconnection in various ways. One way is a reduction in the reconnection rate due to the non-zero magnetospheric mass density. There are other, important ways that magnetospheric ions affect reconnection, such as modification of characteristic length scales and currents within the diffusion region (see, e.g., Toledo-Redondo et al., 2016; André et al., 2016; Dargent et al., 2017; Graham et al., 2017). However, the focus here is on the reconnection rate reduction. This reduction was originally estimated from scaling laws for anti-parallel reconnection by Cassak and Shay (2007) and revised for reconnection with a guide field by Birn et al. (2008). Borovsky et al. (2013) used the formulations from Cassak and Shay (2007) and Birn et al. (2008) to derive the modification of the reconnection rate due to the presence of magnetospheric plasma. This modification to the rate is independent of the magnitude of the guide field. The Borovsky et al. (2013) derivation was rewritten by Fuselier et al. (2016) and the end result is reproduced here as equations (1) and (2):

$$
\begin{gathered}
R=(1+M C)^{-\frac{1}{2}} \\
M C \equiv \frac{\rho_{m} B_{s}}{\rho_{s} B_{m}}
\end{gathered}
$$

In equation (1) and (2), $\mathrm{R}$ is the reduction in the reconnection rate, expressed as a fraction $\leq 1, \mathrm{MC}$ is the mass correction factor, $\rho_{m}$ is the magnetospheric mass density, $B_{s}$ is the magnetosheath magnetic field magnitude, $\rho_{\mathrm{s}}$ is the magnetosheath mass density and $\mathrm{B}_{\mathrm{m}}$ is the magnetospheric magnetic field magnitude. If there is no plasma in the magnetosphere, then $\mathrm{R}=1$. Any finite plasma mass density in the magnetosphere results in $\mathrm{R}$ $<1$, thus equation (1) is a quantitative theoretical prediction of the reduction in the reconnection rate due to the presence of magnetospheric plasma. Equations (1) and (2) are essentially a fluid description of the reconnection rate. PIC simulations (Tenfjord et al., 2019) indicate that $\mathrm{O}^{+}$does reduce the reconnection rate; however, the reduction occurs somewhat differently when the magnetization of the $\mathrm{O}^{+}$is considered in the kinetic simulations. These simulations are new and focus on the Earth's magnetotail. Since the focus in this paper is on the dayside magnetopause and the intent is to connect with previous studies, the fluid description in equations (1) and (2) is used.

This kind of analysis of the relative change in the theoretical reconnection rate is required since experimental determination of the reconnection rate and the potential reduction in this rate is very difficult. The reconnection rate determined from observations at the magnetopause is difficult to determine and not accurate enough to distinguish even the largest possible predicted rate reductions (see, e.g., Cassak \& Fuselier, 2016).

Studies have used equations (1) and (2) or their equivalent to estimate the magnitude of the reduction in the reconnection rate and to determine how often the rate is reduced by a significant fraction (e.g., Wang et al., 2015). One recent survey used observations from the Hot Plasma Composition Analyzers (HPCAs) on the Magnetospheric Multiscale (MMS) mission (Fuselier et al., 2017). This study quantified how often the rate is reduced by $>20 \%$ due to the combined presence of the warm plasma cloak and the ring current. To identify warm plasma cloak intervals, this survey used several criteria, including a lower limit of $1.5 \mathrm{~cm}^{-3}$ on the $\mathrm{H}^{+}$ density in the magnetosphere. With these criteria, the warm plasma cloak was found to be concentrated on the duskside magnetosphere when it was observed within 1.5 hours of a magnetopause crossing by the MMS spacecraft. 
The study also quantified the probability that the reconnection rate would be reduced by $>20 \%$ due to the presence of warm plasma cloak and ring current ions at the magnetopause. The magnetospheric plasma causes a reduction of $>20 \%$ in $\sim 2 \%$ of the MMS magnetopause crossings (Fuselier et al., 2017).

There is an issue with the initial selection criteria of the warm plasma cloak intervals in the Fuselier et al. (2017) survey. In particular, using the $1.5 \mathrm{~cm}^{-3}$ minimum $\mathrm{H}^{+}$density in the magnetosphere as a selection criterion for warm plasma cloak intervals excludes intervals when $\mathrm{O}^{+}$dominates this magnetospheric population. As discussed above, the $\mathrm{O}^{+}$flux dominates ionospheric outflow when geomagnetic activity is high. Therefore, it is possible that there are intervals in the magnetosphere when the $\mathrm{H}^{+}$density is $<1.5 \mathrm{~cm}^{-3}$ and the $\mathrm{O}^{+}$density is, for example, $>0.2 \mathrm{~cm}^{-3}$. For these times, $\mathrm{O}^{+}$dominates the mass density in the magnetosphere by more than a factor of 2 and these times would have been excluded from the survey. As a result of this exclusion, the probability that the reconnection rate is reduced by $>20 \%$ is underestimated.

The purpose of this paper is to investigate when $\mathrm{O}^{+}$dominates the mass density in the magnetosphere and the $\mathrm{H}^{+}$density in the magnetosphere was $<1.5 \mathrm{~cm}^{-3}$. This paper uses the same data set from MMS/HPCA used in Fuselier et al. (2017) to conduct a new survey. The new survey determines how many of the $\mathrm{O}^{+}$-rich warm plasma cloak intervals were missed in the original survey. The predicted reduction in the reconnection rate is computed for a subset of these intervals where the magnetospheric $\mathrm{O}^{+}$density is very high. These results are then combined with the original survey results to obtain a better estimate of the overall probability that the reconnection rate is reduced by $>20 \%$ due to the presence of the warm plasma cloak.

The $\mathrm{O}^{+}$-rich warm plasma cloak intervals are all found to be associated with higher geomagnetic activity and geomagnetic storms. Therefore, a separate investigation is conducted of maximum possible reductions in the reconnection rate during geomagnetic storms. This investigation uses 22 of the largest storm days in the first two dusk-to-dawn sweeps of the dayside magnetopause by the MMS spacecraft.

Section 2 presents an example of an $\mathrm{O}^{+}$-rich warm plasma cloak interval that was missed by the original survey. Section 3 discusses the new survey criteria and the results from this survey, including the connection with high geomagnetic activity and geomagnetic storms. Section 4 discusses overall effects on reconnection from the combined results from the two warm plasma cloak and $\mathrm{O}^{+}$-rich warm plasma cloak surveys. Section 5 discusses a new analysis of warm plasma cloak effects on magnetopause reconnection during geomagnetic storms.

\section{20 September $2015 \mathrm{O}^{+}$-rich warm plasma cloak interval}

Figure 1 shows 20 min of solar wind plasma and magnetic field data from 20 September 2015. Data are convected to the magnetopause. The solar wind magnetic field was slightly southward with a large, positive $B_{Y}$ component and a relatively small $\mathrm{B}_{\mathrm{X}}$ component for most of the interval. The clock angle, derived from the $\mathrm{B}_{\mathrm{Y}}$ and $\mathrm{B}_{\mathrm{Z}}$ components, was $95^{\circ}$ through most of the interval. The solar wind dynamic pressure was $3.3 \mathrm{nPa}$, somewhat higher than the nominal dynamic pressure of $1.9 \mathrm{nPa}$. The moderately high pressure was the result of moderately high solar wind density of $>5 \mathrm{~cm}^{-3}$ and velocity of $\sim 550 \mathrm{~km} / \mathrm{s}$.

Figure 2 shows data from the MMS1 Hot Plasma Composition Analyzer (HPCA) and the Fluxgate Magnetometer (FGM) (Russell et al., 2016; Young et al., 2014) for the corresponding 20 min solar wind interval in Figure 1. At 1100 UT, the spacecraft was located at the duskside magnetopause in the southern hemisphere at X,Y,Z GSM $=(6.3,7.7,-5.2)$ Earth radii $\left(\mathrm{R}_{\mathrm{E}}\right)$. The moderately high solar wind dynamic pressure compressed the magnetosphere so that MMS crossed the magnetopause at a radial distance of $11.2 \mathrm{R}_{\mathrm{E}}$ from Earth. The magnetospheric activity was elevated with a 3-hour Kp index of 5 and this crossing occurred during a geomagnetic storm. At the time of the crossing, the Dst index was - $71 \mathrm{nT}$ and the storm Dst ultimately reached a minimum value of $-75 \mathrm{nT}$ at $1600 \mathrm{UT}$.

The panels in Figure 2 are, from top to bottom, the energy-time spectrogram of the omnidirectional $\mathrm{H}^{+}$flux, the $\mathrm{H}^{+}$density, the energy-time spectrogram of the omnidirectional $\mathrm{O}^{+}$flux, the $\mathrm{O}^{+}$density, and the $\mathrm{B}_{\mathrm{Z}}$ GSM component of the magnetic field. A region identifier is provided above the top panel. The spacecraft was in the magnetosheath from 1050 UT to about 1056 UT. The $\mathrm{H}^{+}$density in the magnetosheath was about $20 \mathrm{~cm}^{-3}$ and the $\mathrm{H}^{+}$fluxes peaked between $100 \mathrm{eV}$ and $1000 \mathrm{eV}$. From $1056 \mathrm{UT}$ to the magnetopause crossing at 1059 UT, the spacecraft was in the magnetosheath boundary layer (MSBL) (Cowley, 1982). This region is 


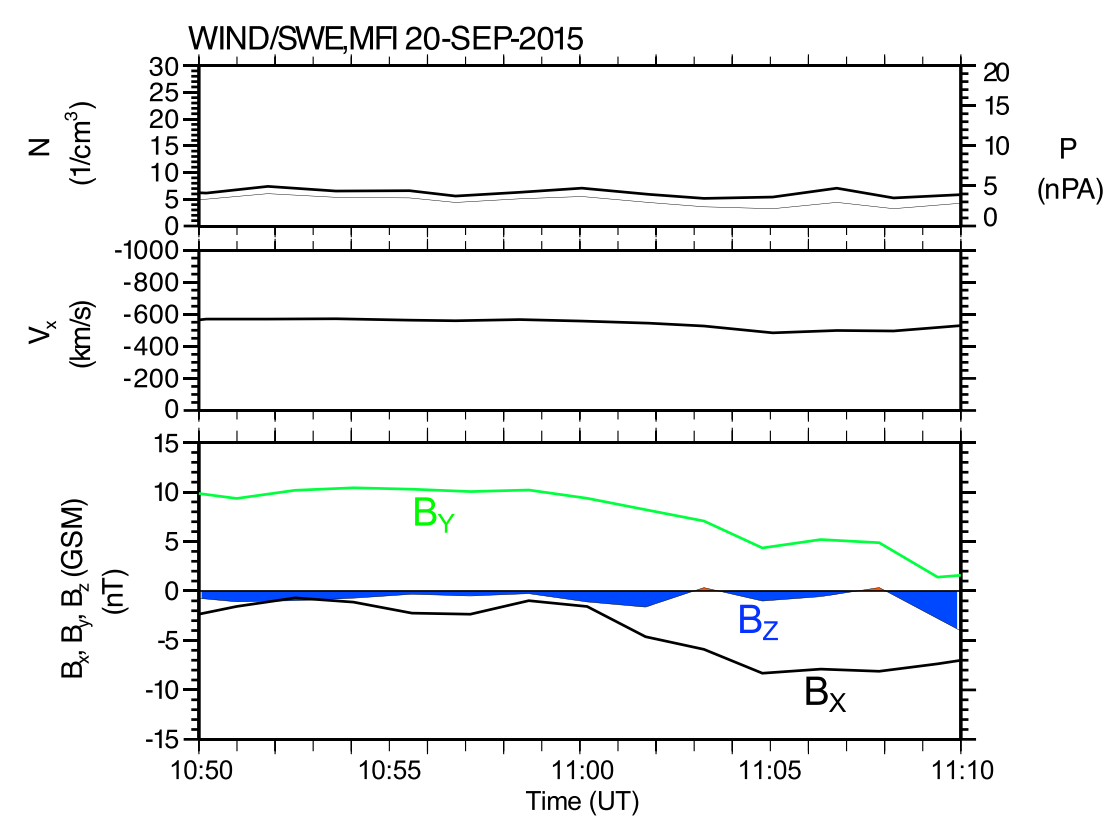

Figure 1. Solar wind data convected to the magnetopause. Top to bottom is the solar wind density and dynamic pressure, the solar wind $V_{X}$ velocity, and the 3 components of the IMF. The solar wind density, dynamic pressure, and velocity were all relatively high compared to their nominal values and also relatively steady throughout the interval. Through most of the interval, the magnetic field was slightly southward with a large $\mathrm{B}_{\mathrm{Y}}$ component and a relatively small $\mathrm{B}_{\mathrm{X}}$ component.

characterized by higher $\mathrm{H}^{+}$fluxes at energies greater than $10 \mathrm{keV}$ and significantly higher $\mathrm{O}^{+}$fluxes at energies greater than about $1 \mathrm{keV}$, when compared to the magnetosheath fluxes for these species and energies. The MSBL is the reconnection layer adjacent to the magnetopause that is on open field lines that thread the magnetopause. The higher fluxes of energetic $\mathrm{H}^{+}$and $\mathrm{O}^{+}$are magnetosheath and magnetospheric $\mathrm{H}^{+}$and magnetospheric $\mathrm{O}^{+}$ions that are propagating along open field lines. Thus, the presence of the MSBL indicates that reconnection was occurring at the magnetopause, although the reconnection X-line is likely remote from the spacecraft location. Although not shown in Figure 2, there is also evidence for a reconnection jet in the low latitude boundary layer (LLBL) at 1059 UT and again at $1101 \mathrm{UT}$.

Inside the magnetosphere from about 1059:30 UT to $1101 \mathrm{UT}$ and from about $1103 \mathrm{UT}$ to $1108 \mathrm{UT}$, the $\mathrm{H}^{+}$ density was mostly less than $1 \mathrm{~cm}^{-3}$. The $\mathrm{O}^{+}$density exceeded $1 \mathrm{~cm}^{-3}$ at one point and was above $0.6 \mathrm{~cm}^{-3}$ for the magnetospheric intervals in Figure 2. In fact, the magnetospheric $\mathrm{O}^{+}$densities in Figure 2 are some of the highest $\mathrm{O}^{+}$densities ever observed by MMS near the magnetopause.

The $\mathrm{H}^{+}$plasma in the magnetosphere had energies between about $100 \mathrm{eV}$ and $40 \mathrm{keV}$, the highest energy measured by HPCA. The $\mathrm{O}^{+}$fluxes peaked at about $5 \mathrm{keV}$ and also extended up to the highest energy measured by HPCA. These energy ranges are consistent with the combined warm plasma cloak and ring current populations. The spacecraft was in the LLBL from 1101 UT to 1103 UT and after 1108 UT. In the LLBL, the $\mathrm{H}^{+}$density was intermediate between the density in the magnetosphere and the magnetosheath and there was substantial $\mathrm{O}^{+}$. The $\mathrm{Z}$ component of the magnetic field in the magnetosheath was only slightly less than zero, consistent with the slightly southward interplanetary magnetic field (IMF). In the magnetosphere, the $\mathrm{Z}$ component of the magnetic field was variable but generally greater than zero.

$\mathrm{O}^{+}$dominated the mass density in the magnetospheric intervals in Figure 2. In particular, the $\mathrm{O}^{+}$mass density was $>10 \mathrm{~cm}^{-3}$-amu and the $\mathrm{H}^{+}$mass density was $<1.5 \mathrm{~cm}^{-3}$-amu. Although not shown in Figure 2, the $\mathrm{He}^{+}$mass density was $<0.02 \mathrm{~cm}^{-3}$-amu and did not contribute appreciably to the total mass density. The low $\mathrm{He}^{+}$content relative to $\mathrm{O}^{+}$is another characteristic of the warm plasma cloak (Fuselier et al., 2017). The average mass density in the magnetosphere (dominated by $\mathrm{O}^{+}$) was an appreciable fraction of the $26 \mathrm{~cm}^{-3}$-amu magnetosheath mass density (dominated by $\mathrm{H}^{+}$). Therefore, the magnetospheric plasma 


\section{MMS1/HPCA Mag}

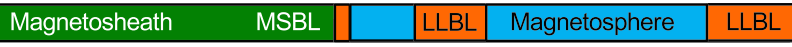

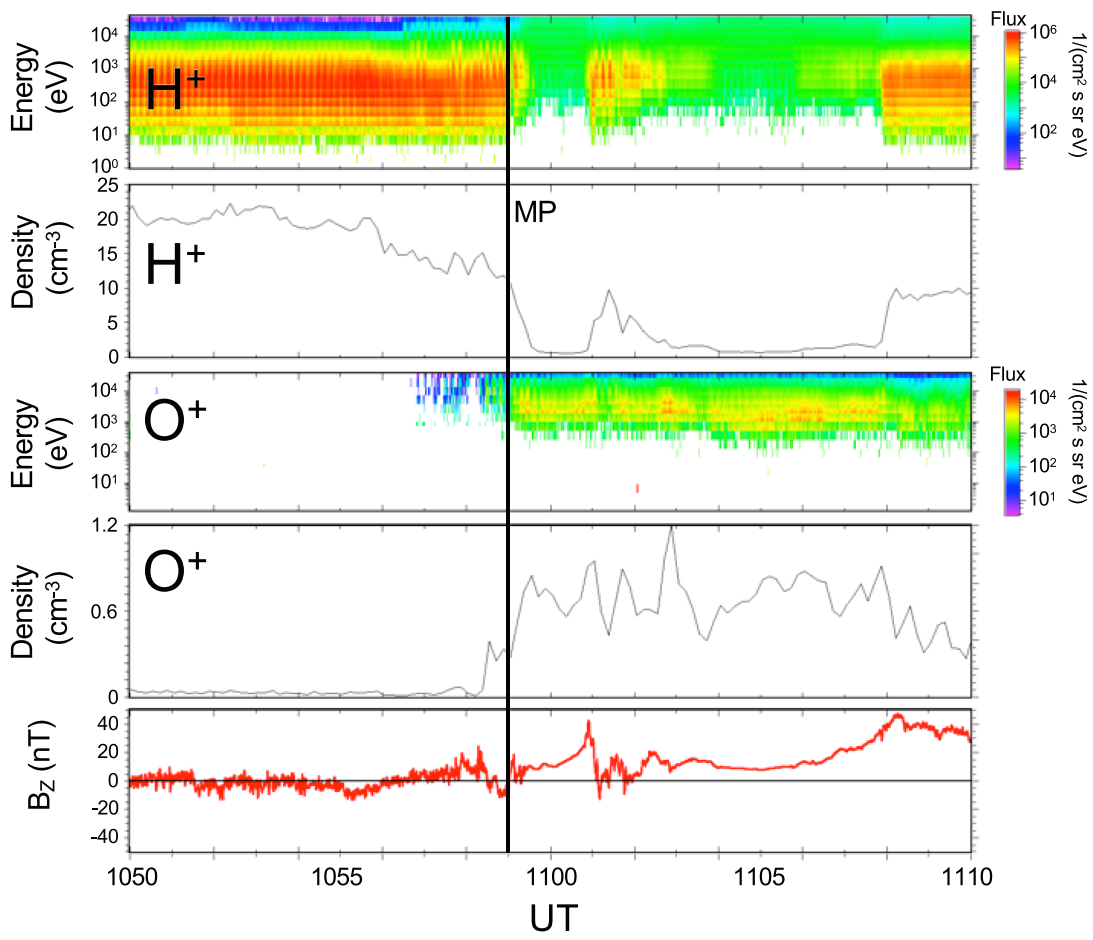

Figure 2. Example of an $\mathrm{O}^{+}$-rich warm plasma cloak interval near the magnetopause during a geomagnetic storm. The solar wind data for this interval is in Figure 1. Top to bottom are the $\mathrm{H}^{+}$energy-time spectrogram, the $\mathrm{H}^{+}$density, the $\mathrm{O}^{+}$energy-time spectrogram, the $\mathrm{O}^{+}$density, and the $\mathrm{B}_{Z}$ GSM component of the magnetic field. $\mathrm{O}^{+}$is observed in the magnetosheath boundary layer, which is evidence of reconnection at the magnetopause and escape of energetic $\mathrm{O}^{+}$ along open field lines into the magnetosheath. The $\mathrm{O}^{+}$density in the magnetosphere is very high, with a maximum density of $1.2 \mathrm{~cm}^{-3}$ and an average density $>0.6 \mathrm{~cm}^{-3}$. The energy range of the $\mathrm{H}^{+}$and $\mathrm{O}^{+}$in the magnetosphere and high $\mathrm{O}^{+}$content are indicative of the mix between two sources of magnetospheric ions: the ring current and the warm plasma cloak. $\mathrm{O}^{+}$dominates the mass density in this $\mathrm{O}^{+}$-rich warm plasma cloak interval.

had a significant, local effect on magnetic reconnection for this magnetopause crossing. Furthermore, because the $\mathrm{H}^{+}$density in the magnetosphere was $<1.5 \mathrm{~cm}^{-3}$ most of the time, this $\mathrm{O}^{+}$-rich warm plasma cloak interval was missed in the original survey of the warm plasma cloak by Fuselier et al. (2017).

\section{3. $\mathrm{O}^{+}$-Rich Warm Plasma Cloak Survey Description and Survey Results}

The observations in Figure 2 demonstrate the need to revise and augment the original survey of the effects of the warm plasma cloak on magnetic reconnection. In this section, the criteria imposed on this new survey and results from the survey are discussed.

The starting data set is from MMS3 and is the same set used in the original survey of Fuselier et al. (2017). The spacecraft were very close together $(\sim 10-50 \mathrm{~km}$ separations) and, for the $10 \mathrm{~s}$ time resolution of HPCA, measurements from all spacecraft are essentially the same. MMS3 was chosen here because it was used in the original survey. Data are from 1 September 2015 to 8 March 2016, the first sweep of the dayside magnetopause for the mission. From September 2015 to early January 2016 the data set consisted of approximately 3200 full and partial magnetopause crossings including approximately 1200 full crossings (Petrinec et al., 2016). The entire interval from September 2015 to March 2016 consists of over 4500 full and partial magnetopause crossings including 1500 full crossings from the magnetosphere to the magnetosheath like the one in Figure 2. MMS3 made approximately 650,000 10-s measurements from a radial distance of $>7$ $\mathrm{R}_{\mathrm{E}}$ from the Earth and within 1.5 hours of a magnetopause crossing. The 650,000 measurements are from 190 orbits (each orbit is about 1 day) or 380 orbit legs and 10 seconds is the time resolution for a full 3-D 
distribution function measurement from HPCA. An orbit leg is defined as the outbound (inbound) trajectory before (after) apogee. The following three criteria, used in Fuselier et al. (2017) and used in this present study, ensured that the spacecraft was in the magnetosphere near the magnetopause and not in the LLBL or magnetosheath:

1) The spacecraft was at a radial distance of $>7 R_{E}$ from the Earth and within 1.5 hours of a magnetopause crossing

2) The $B_{Z}$ GSM component of the magnetic field was positive.

3) The omnidirectional $\mathrm{He}^{2+}$ flux at $1 \mathrm{keV}$ was $<100\left(\mathrm{~cm}^{2} \mathrm{~s} \mathrm{sr} \mathrm{eV}\right)^{-1}$ and the omnidirectional $\mathrm{He}^{2+}$ flux at 5 $\mathrm{keV}$ was $<2000\left(\mathrm{~cm}^{2} \mathrm{~s} \mathrm{sr} \mathrm{eV}\right)^{-1}$.

In Fuselier et al. (2017), the fourth criterion was that the $\mathrm{H}^{+}$density was $>1.5 \mathrm{~cm}^{-3}$. This criterion is replaced with the following new criterion for the density in the magnetosphere. The new criterion excludes the intervals in the original survey and includes intervals where the magnetospheric $\mathrm{O}^{+}$density was dominant:

4) The $\mathrm{H}^{+}$density was $<1.5 \mathrm{~cm}^{-3}$ and the $\mathrm{O}^{+}$density was $\geq 0.2 \mathrm{~cm}^{-3}$.

Using these 3 criteria plus the requirements that the spacecraft was greater than $7 \mathrm{R}_{\mathrm{E}}$ from the Earth and within 1.5 hours of the magnetopause crossing, 97010 -s measurements of $\mathrm{O}^{+}$-rich warm plasma cloak spread over 13 days were identified. These 970 measurements represent approximately a $10 \%$ increase in the total warm plasma cloak measurements from the original survey since the original survey had 10,400 10 -s warm plasma cloak measurements. Thus, the warm plasma cloak is $\mathrm{O}^{+}$-rich approximately $10 \%$ of the time in the magnetosphere in the vicinity of the magnetopause.

Figure 3 (upper panels) shows the location of these 970 measurements projected into the $\mathrm{X}-\mathrm{Y}_{\mathrm{GSM}}$ plane (left), the $\mathrm{X}-\mathrm{Z}_{\mathrm{GSM}}$ plane (middle), and the $\mathrm{Y}-\mathrm{Z}_{\mathrm{GSM}}$ plane (right). The $\mathrm{O}^{+}$-rich warm plasma cloak is distributed almost evenly over the local time and latitudes that are covered by the MMS spacecraft. This even distribution is in contrast to the warm plasma cloak measurements in Fuselier et al. (2017), which show a distinct concentration on the duskside. However, if the local time occurrence of the warm plasma cloak and $\mathrm{O}^{+}$-rich warm plasma cloak were combined, they would still show an enhancement on the duskside because the $\mathrm{O}^{+}$rich warm plasma cloak is only $10 \%$ of the total number of cloak measurements.

To determine the effect on reconnection at the magnetopause, the same criterion used in Fuselier et al. (2017) is used here to select the highest mass densities in the magnetosphere. In particular, the high-density data set consists of 10-s intervals when the mass density is $>10 \mathrm{~cm}^{-3}$-amu or, equivalently, an appreciable percentage of the most probable mass density in the magnetosheath of $20 \mathrm{~cm}^{-3}$-amu (Cassak \& Fuselier, 2016). The locations of the 245 10-s measurements over 13 days are shown in the bottom 3 panels of Figure 3. The viewing planes are the same as in the upper panels. The high-density data set is still distributed almost evenly over local time and latitude.

The 245 10-s measurements over 13 orbits are compared to the 543 10-s measurements with mass density greater than $10 \mathrm{~cm}^{-3}$-amu from the original survey. The $\mathrm{O}^{+}$-rich warm plasma cloak intervals increase the high-mass density intervals in the magnetosheath by nearly $50 \%$. In other words, the high-mass density warm plasma cloak is often $\mathrm{O}^{+}$-rich.

The even distribution of the high-mass density, $\mathrm{O}^{+}$-rich warm plasma cloak over all local times indicates that there is some other external factor that determines the $\mathrm{O}^{+}$content of the cloak. The external factor that determines the $\mathrm{O}^{+}$content in the magnetosphere is, ultimately, the solar wind. All 13 orbits are associated with geomagnetic storms and many of these storms are the strongest storms of 2015 and 2016. The intervals were not selected based on geomagnetic activity. Therefore, the fact that all 13 are assocated with some of the strongest storms is significant.

\section{4. $\mathrm{O}^{+}$-Rich Warm Plasma Cloak Effect on Reconnection}

The predicted effect on reconnection is computed from Equations (1) and (2). For each of the 13 orbits where the $\mathrm{O}^{+}$-rich warm plasma cloak mass density was high, the average mass density (including $\mathrm{H}^{+}$and $\mathrm{He}^{2+}$ ) in the magnetosheath and the average magnetosheath magnetic field magnitude $\left(\rho_{\mathrm{s}}, \mathrm{B}_{\mathrm{s}}\right.$, respectively in equation (2)) were determined over a $\sim 5$-min interval that was representative of the region near the 


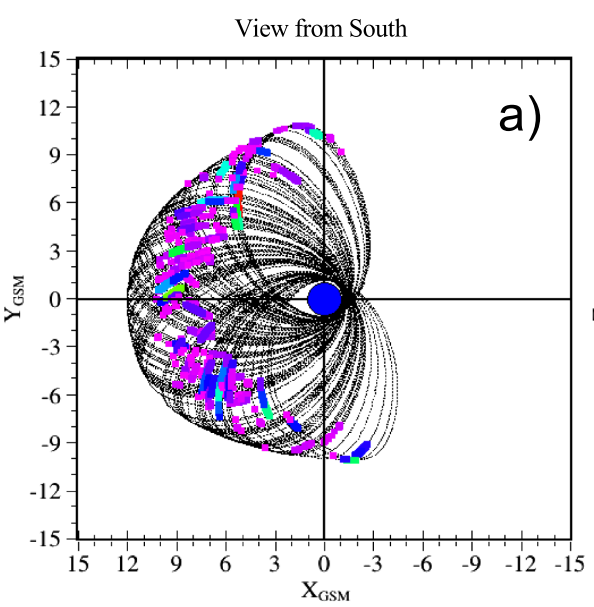

Plot created by SDDAS/gPlot - -1. Mukherjece, et al. Gencerated on Thu Jul 18 20:29:(6) 2019.

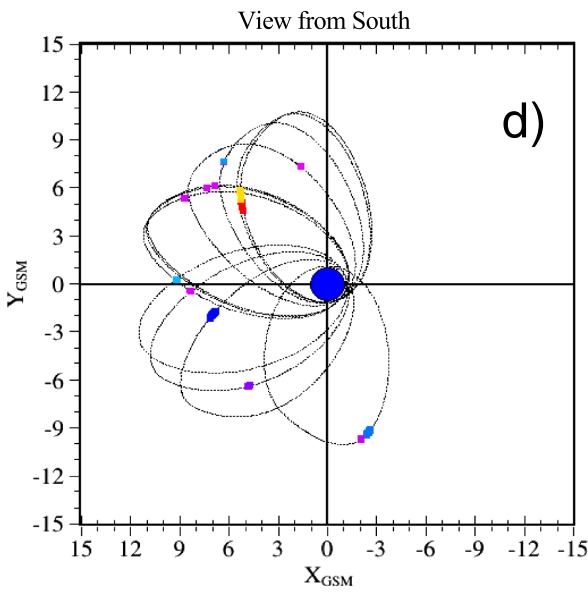

01 September 2015 - 01 April 2016

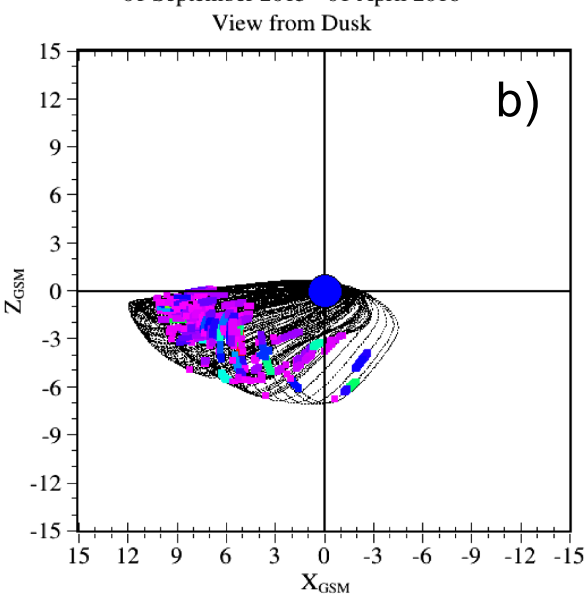

01 September 2015 - 01 April 2016

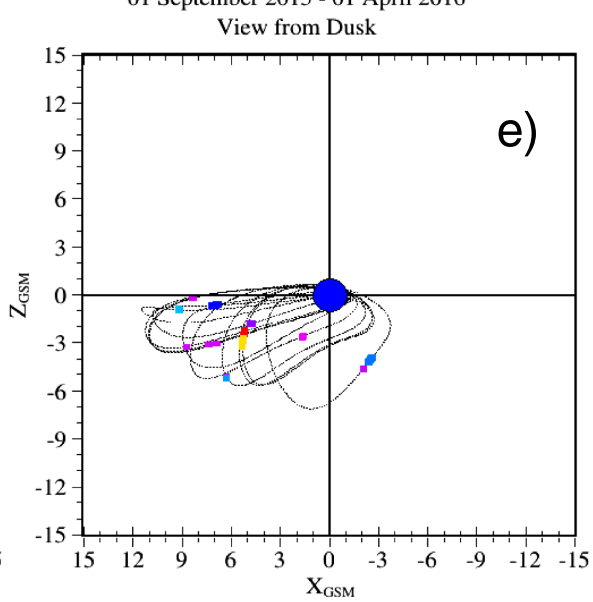

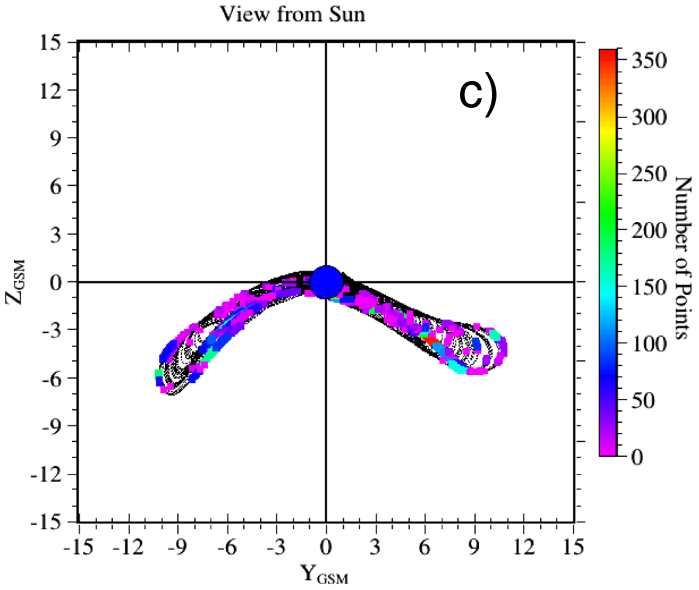

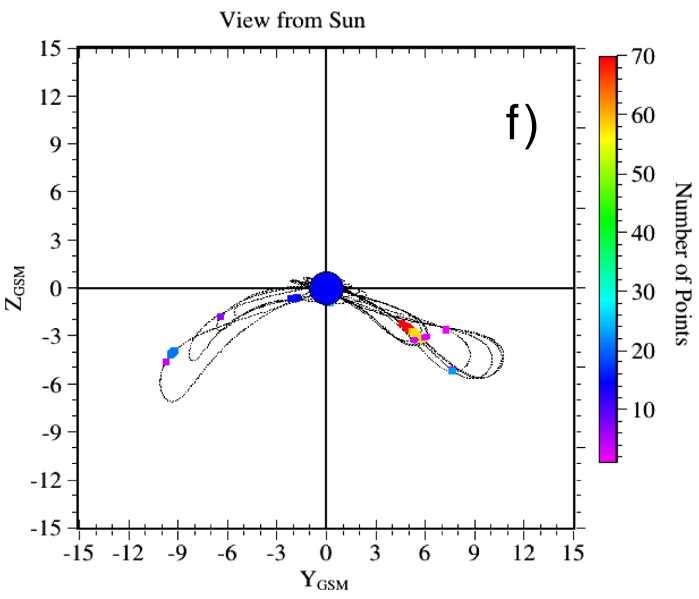

Figure 3. (top row) Distribution of $\mathrm{O}^{+}$-rich warm plasma cloak intervals from the MMS phase 1a from September 2015 to March 2016. Orbits are shown in grey and the number of 10-s intervals that met the $\mathrm{O}^{+}$-rich warm plasma cloak criteria are color coded on the right. The color scale shows the number of 10 -s intervals in 1 hour. The $\mathrm{O}^{+}$-rich cloak intervals are distributed relatively evenly over the ranges of local time and latitude that MMS accesses. (bottom row) same as the top row except that the mass density is greater than $10 \mathrm{~cm}^{-3}$-amu. The high-density, $\mathrm{O}^{+}$-rich warm plasma cloak is also distributed relatively evenly over local time and latitude.

magnetopause crossing. For example, in the event in Figure 2, the magnetosheath interval was from 1050 UT to 1055 UT. For the magnetosphere, all of the continuous or nearly continuous 10-s intervals were used to compute an average mass density (including $\mathrm{H}^{+}, \mathrm{He}^{2+}, \mathrm{He}^{+}$and $\mathrm{O}^{+}$) and an average total magnetic field magnitude $\left(\rho_{\mathrm{m}}, \mathrm{B}_{\mathrm{m}}\right.$, respectively in equation (2)). The 13 orbit legs had a variable number of 10-s magnetospheric intervals ranging from 6 to over 100. Then, the maximum mass density observed during the magnetospheric time intervals was selected. Continuing with the example in the event in Figure 2, the average magnetospheric mass density was computed from 1059:30 UT to 1101 UT and from 1102 UT to 1108 UT, the blue shaded areas in the region identifier bar at the top of Figure 2. The maximum mass density occurred during the 10-s measurement centered at 1102:51 UT, when the $\mathrm{O}^{+}$density peaked at $1.21 \mathrm{~cm}^{-3}$. Both the average and the maximum mass density are used to separately calculate the reduction in the reconnection rate in order to emphasize the fact that the warm plasma cloak mass density is highly variable (see also, Fuselier, Burch, et al., 2016).

These data were used in equation (2) to determine MC. The reduction in the reconnection rate, $\mathrm{R}$, was then computed from equation (1), using MC from equation (2). The reconnection rate reduction averaged over a portion of an orbit leg with $\mathrm{O}^{+}$-rich warm plasma cloak was combined with the average rate reductions for the warm plasma cloak survey from Fuselier et al. (2017). Figure 4, left panel, shows the combined result. 

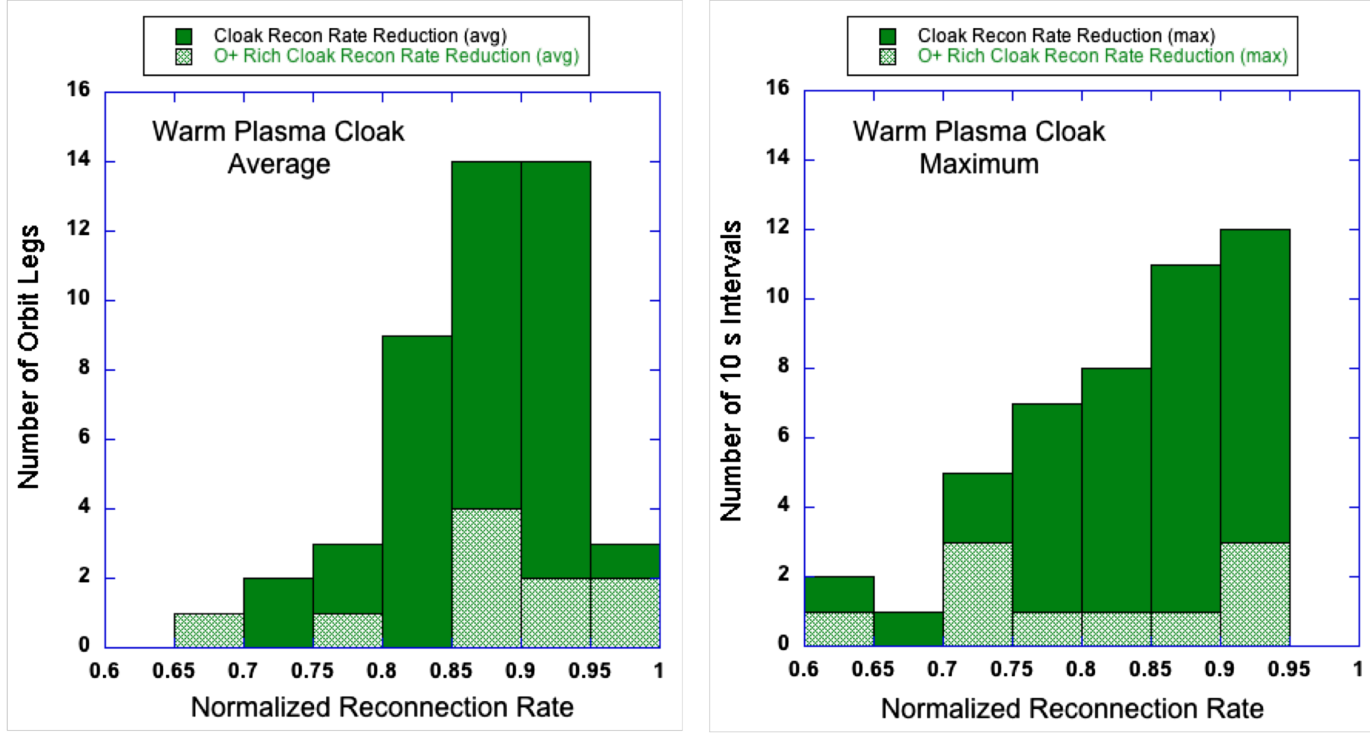

Figure 4. Histograms of the combined warm plasma cloak and $\mathrm{O}^{+}$-rich warm plasma cloak normalized reconnection rate. The left panel shows the rates for the average over the cloak intervals and the right panel shows the rates for the maximum within a cloak interval. The $\mathrm{O}^{+}$-rich warm plasma cloak adds to the statistics but does not change the overall profiles of the reconnection rates. There are only 6 orbit legs where the average over the warm plasma cloak interval reduces the reconnection rate by $>20 \%$. Similarly, there are only thirteen 10 -s intervals where the warm plasma cloak maximum reduces the reconnection rate by $20 \%$.

The warm plasma cloak orbit legs from Fuselier et al. (2017) are in solid, dark green and the $\mathrm{O}^{+}$-rich warm plasma cloak orbit legs from the survey described in Section 3 are in light green. Because some of the 10-s intervals in 3 orbit legs had $\mathrm{H}^{+}$densities both greater than and less than $1.5 \mathrm{~cm}^{-3}$, they would be double counted in Figure 4. These 3 intervals are counted as standard, and not $\mathrm{O}^{+}$-rich, warm plasma cloak intervals. In any case, the reconnection rate reduction for the $10 \mathrm{O}^{+}$-rich warm plasma cloak orbit legs are spread relatively evenly over the range shown in Figure 4 . Thus, for the average reconnection rate reduction, the $\mathrm{O}^{+}$-rich warm plasma cloak intervals add to the statistics. However, their addition is not significant enough to change the overall result. Without the $\mathrm{O}^{+}$-rich warm plasma cloak, there are only 4 out of 380 total orbit legs where the reconnection rate is reduced by $>20 \%$. Taking into consideration the $\mathrm{O}^{+}$-rich warm plasma cloak adds only two additional orbit legs to this total. Thus, the reconnection rate is reduced by $>20 \%$ in about $2 \%$ of the magnetopause encounters due to the presence of the warm plasma cloak.

There is a similar result for the reduction in the reconnection rate using the maximum mass densities during these orbit legs. Figure 4, right panel, shows the combined warm plasma cloak and $\mathrm{O}^{+}$-rich warm plasma cloak results. Again, the $\mathrm{O}^{+}$-rich cloak results add to the statistics, but do not change the overall profile. There are 15 out of 380 total orbit legs where the reconnection rate is reduced by $>20 \%$. Thus, the reconnection rate is reduced by $>20 \%$ in about $4 \%$ of the magnetopause encounters at some instant in time due to the presence of the warm plasma cloak.

Figure 5 shows the average reconnection rate versus the 3-hour Kp index for the warm plasma cloak intervals (solid green squares) and the $\mathrm{O}^{+}$-rich warm plasma cloak (open green squares). The two types of warm plasma cloak have different distributions of 3-hour Kp indices. The warm plasma cloak intervals have an average 3-hour $\mathrm{Kp}$ of 3 while the $\mathrm{O}^{+}$-rich warm plasma cloak have an average 3-hour $\mathrm{Kp}$ of 5 . Clearly, the $\mathrm{O}^{+}$-rich warm plasma cloak is observed near the magnetopause during disturbed times and, as pointed out above, all of the $\mathrm{O}^{+}$-rich warm plasma cloak intervals are associated with days when there were geomagnetic storms of varying strengths.

\section{The Warm Plasma Cloak During Geomagnetic storms}

When combined with the total number of orbit legs used in the original warm plasma cloak survey, Figure 4 shows that reconnection is adversely affected (i.e., reduced by $>20 \%$ ) in only $2-4 \%$ of the 


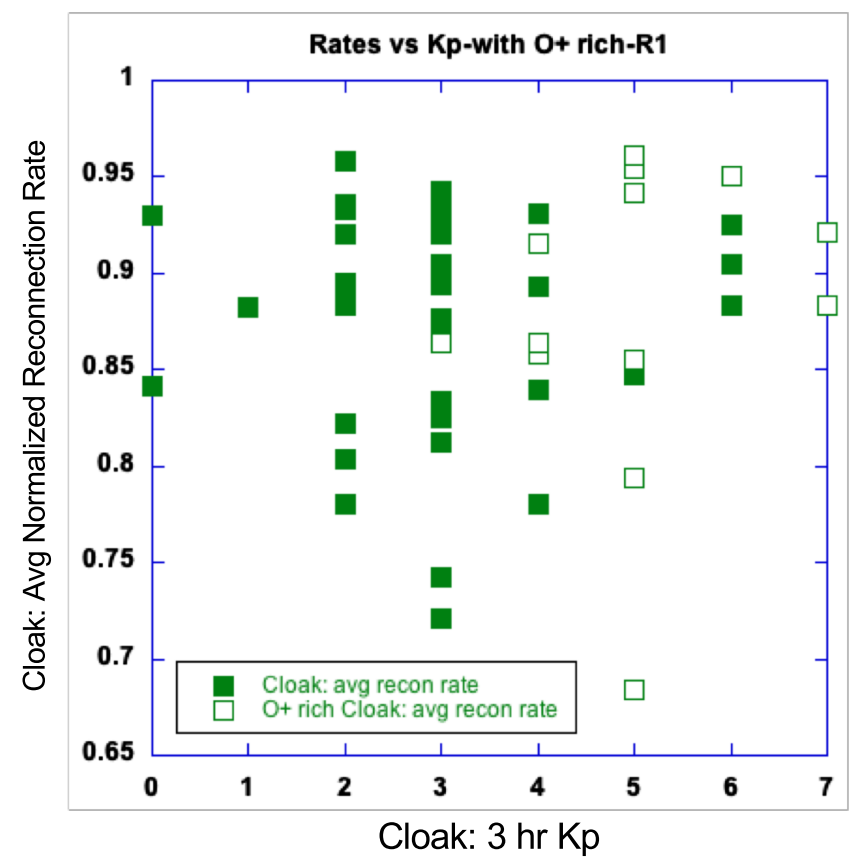

Figure 5. Average normalized reconnection rate versus 3-hr Kp for the warm plasma cloak and the $\mathrm{O}^{+}$-rich warm plasma cloak. The average 3-hr $\mathrm{Kp}$ for the warm plasma cloak intervals is 3 while the average for the $\mathrm{O}^{+}$rich warm plasma cloak is 5 . The higher average $\mathrm{Kp}$ indicates that the warm plasma cloak is $\mathrm{O}^{+}$-rich during higher geomagnetic activity, consistent with the high-latitude origin of the warm plasma cloak. magnetopause encounters of the MMS spacecraft. However, Figure 5 shows that the warm plasma cloak is $\mathrm{O}^{+}$-rich during disturbed times. Therefore, the statistics on the effect of the warm plasma cloak on reconnection is biased by the large number of magnetopause encounters during geomagnetically quiet conditions. This bias is particularly significant because the observations were made from September 2015 to March 2016, during the declining phase of a relatively weak solar cycle.

This bias raises a different question: What is the warm plasma cloak effect on reconnection rates at the magnetopause during disturbed magnetospheric conditions? To answer this question, 22 geomagnetic storm days were selected from the first two dusk-to-dawn, dayside magnetopause encounters of the MMS spacecraft. The list of geomagnetic storm days is available at https://www.spaceweatherlive.com/en/auroral-activity/top-50-geomagnetic-storms. The storm days are listed by storm intensity as defined by a sum of the 3-hr Kp index during the day. While there is a correlation between the sum of the $3-\mathrm{hr} \mathrm{Kp}$ indices and minimum Dst in a storm, in general, an intense storm in the list is characterized by sustained high Kp values during the day and not necessarily the minimum Dst during the storm. The selected storm days occur during the two MMS dayside magnetopause encounter intervals from September 2015 through March 2016 and from September 2016 through March 2017. These two intervals were defined as prime mission phases 1a and $1 \mathrm{~b}$ (Fuselier et al., 2016) and the time interval for this study is twice as long as the one used for the study in Sections III and IV. MMS was required to have a full magnetopause crossing during the storm day so that the magnetosheath and magnetospheric plasma could be evaluated.

The 22 storm days are listed in Table 1, along with the time of the nearest magnetopause encounter, the 3-hr Kp index for that encounter time, the minimum Dst of the storm, and the time of the minimum Dst. The 22 storm days listed in Table 1 include the geomagnetically active times during phase 1a when the $\mathrm{O}^{+}$-rich warm plasma cloak was observed, but also include several additional geomagnetically disturbed days during phase $1 \mathrm{~b}$. All of these additional storms have $\mathrm{O}^{+}$-rich warm plasma cloak intervals. Storm days were chosen starting at the top of the lists for the 3 years and selecting the 22 most disturbed storm days during phase $1 \mathrm{a}$ and $1 \mathrm{~b}$. The selection was cutoff at 22 because this study focused on the strongest geomagnetic storms of phase $1 \mathrm{a}$ and $1 \mathrm{~b}$ and the weaker storms had Dst $>-45 \mathrm{nT}$. The intervals chosen to represent the magnetospheric density and magnetic field during disturbed times were not necessarily associated with the minimum in Dst or the maximum 3-hour Kp on a given day. Rather, they were chosen to be the several-minute intervals with the highest average magnetospheric $\mathrm{O}^{+}$density within 1.5 hours of an MMS magnetopause crossing during the storm day. Within that interval, the average magnetospheric mass density was computed and the time of the maximum $\mathrm{O}^{+}$density was used to compute the maximum magnetospheric mass density. These selections were made to maximize the estimate of the effect on magnetic reconnection by the presence of magnetospheric plasma. An example of one of the storm day intervals within 1.5 hours of a magnetopause crossing is shown in Figure 2. The interval with the highest average $\mathrm{O}^{+}$density was from 1102:40 UT to 1106:39 UT and the peak $\mathrm{O}^{+}$density was at 1102:51 UT.

Figure 6 shows the average and maximum normalized reconnection rates for the top geomagnetic storm days in Table 1 . The distribution is similar to that in Figure 4 except that, during geomagnetically disturbed times, there are more instances when the warm plasma cloak has a significant effect on the reconnection rate. The average over the magnetospheric interval and the maximum $\mathrm{O}^{+}$density during the interval show that reconnection is adversely affected in $22 \%$ and $27 \%$ of the storm days. Thus, the reconnection rate is reduced by $>20 \%$ at least sometime during one in four geomagnetically disturbed times. 
Table 1

22 Top storm days from MMS phases $1 a$ and $1 b$ that were used to determine the effect of the warm plasma cloak on reconnection during geomagnetically disturbed times.

\begin{tabular}{lcccc}
\hline $\begin{array}{l}\text { Storm Day } \\
\text { MM/DD/YY }\end{array}$ & $\begin{array}{c}\text { Minimum } \\
\text { Dst (nT) }\end{array}$ & $\begin{array}{c}\text { Hour of } \\
\text { minimum Dst }\end{array}$ & $\begin{array}{c}\text { MMS Magnetopause } \\
\text { Crossing Time (hhmm) }\end{array}$ & $\begin{array}{c}\text { 3-hr Kp at } \\
\text { magnetopause crossing }\end{array}$ \\
\hline $09 / 07 / 15$ & -70 & 21 & 2106 & $6-$ \\
$09 / 09 / 15$ & -98 & 13 & 0851 & 60 \\
$09 / 11 / 15$ & -81 & 15 & 0929 & $6+$ \\
$09 / 20 / 15$ & -75 & 16 & 1059 & $5+$ \\
$10 / 07 / 15$ & -124 & 23 & 1906 & $7+$ \\
$10 / 08 / 15$ & -92 & 1 & 0702 & $6-$ \\
$11 / 07 / 15$ & -87 & 7 & 0154 & $5-$ \\
$11 / 10 / 15$ & -58 & 14 & 1406 & $5+$ \\
$12 / 20 / 15$ & -155 & 22 & 2018 & $7-$ \\
$12 / 21 / 15$ & -148 & 2 & 1032 & $4-$ \\
$12 / 31 / 15$ & -93 & 24 & 2243 & $6-$ \\
$01 / 01 / 16$ & -110 & 1 & 0913 & $3+$ \\
$01 / 20 / 16$ & -93 & 17 & 1829 & $5-$ \\
$01 / 21 / 16$ & -56 & 1 & 0848 & $5+$ \\
$02 / 16 / 16$ & -57 & 20 & 1424 & $5+$ \\
$02 / 17 / 16$ & -52 & 24 & 0446 & $3+$ \\
$03 / 06 / 16$ & -98 & 22 & 1821 & 60 \\
$10 / 25 / 16$ & -59 & 18 & 2010 & $5+$ \\
$10 / 26 / 16$ & -52 & 5 & 0927 & $6-$ \\
$10 / 29 / 16$ & -64 & 4 & 0836 & $5-$ \\
$11 / 25 / 16$ & -46 & 6 & 1628 & $4+$ \\
$03 / 27 / 17$ & -74 & 15 & 1315 & $4+$ \\
\hline
\end{tabular}

Figure 7 shows how the average reconnection rate is related to the 3-hr $\mathrm{Kp}$ of the magnetopause crossing time. The average 3-hr Kp for all the interval is 5. There is a suggested trend in Figure 7: higher magnetospheric activity leads to greater predicted reduction in the reconnection rate. However, the scatter is very large and therefore this trend is only suggestive.
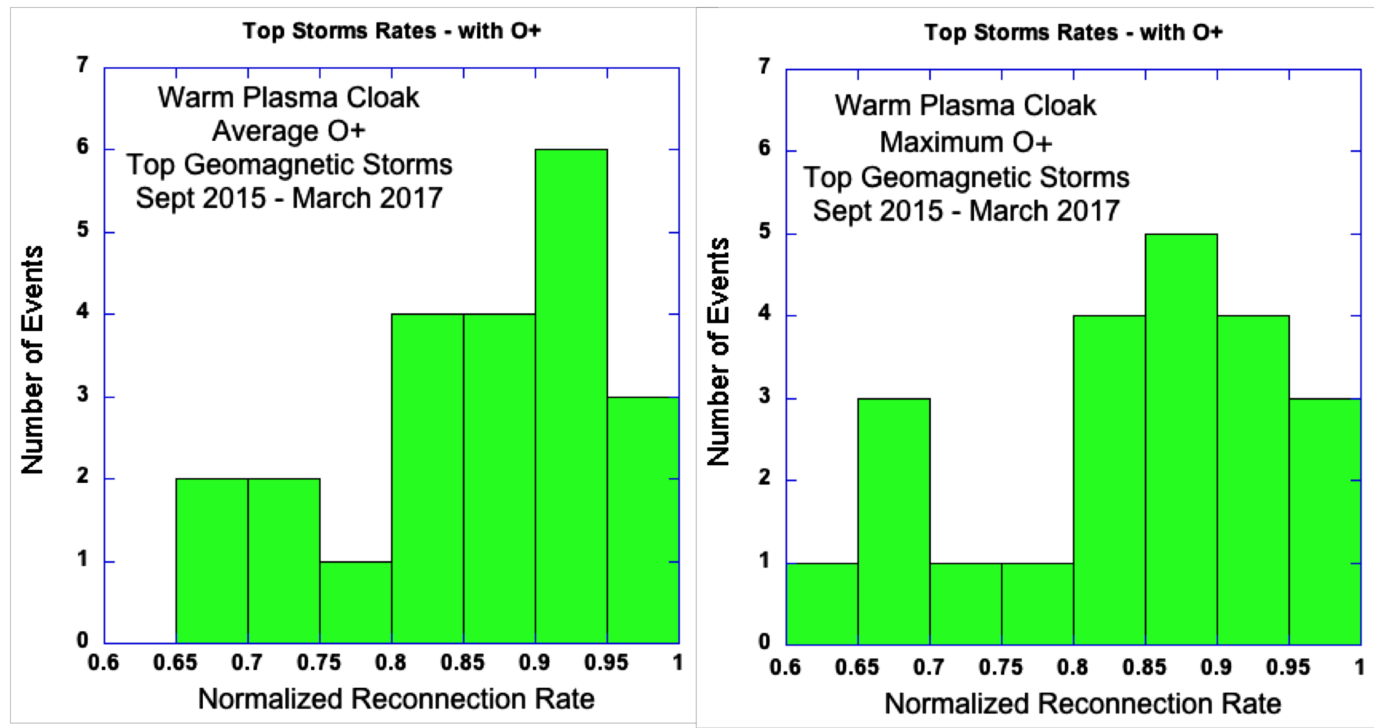

Figure 6. Histograms of the normalized reconnection rate for the average and maximum $\mathrm{O}^{+}$density in the warm plasma cloak for 22 of the top storm days observed during 2015, 2016, and 2017. The presence of the warm plasma cloak reduces the reconnection rate by $>20 \%$ in $\sim 25 \%$ of the top geomagnetic storms at least sometime during the storm interval. 


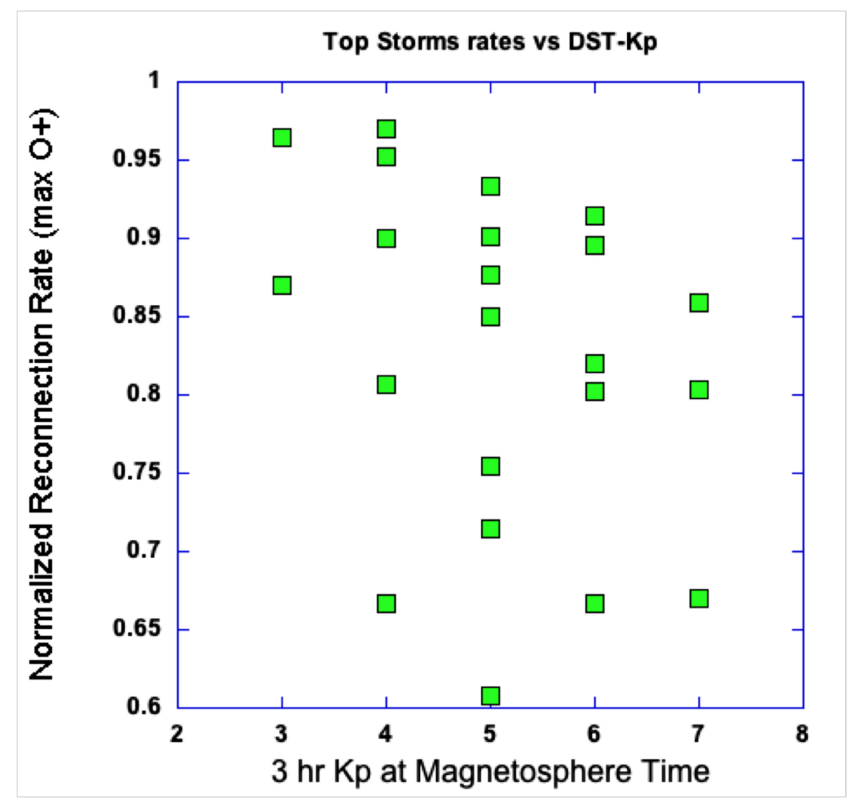

Figure 7. Normalized reconnection rate versus 3-hr Kp for the 22 top storm days in Figure 6. The average Kp for all the intervals is 5 and there is a general trend that higher $\mathrm{Kp}$ results in a larger reduction in the reconnection rate at the magnetopause.

\section{Discussion and Conclusions}

This paper reports on instances when warm plasma cloak $\mathrm{O}^{+}$dominates the magnetospheric ion population near the magnetopause. In a previous survey of the effects on reconnection by the presence of the warm plasma cloak (Fuselier et al., 2017), these instances were missed. As a result, the effect of the warm plasma cloak on the reconnection rate was underestimated.

The same data set used in the previous survey was used to conduct a new survey. In the new survey, $\mathrm{O}^{+}$-rich warm plasma cloak intervals were identified and the effect on reconnection was estimated. While these $\mathrm{O}^{+}$-rich warm plasma cloak intervals add to the statistics, they do not significantly change the overall result that the warm plasma cloak reduces the reconnection rate by $>20 \%$ in only $2 \%$ to $4 \%$ of the magnetopause encounters by the MMS spacecraft. However, the warm plasma cloak intervals from the previous survey are dominated by geomagnetically quiet times.

An important result from this new survey was that the $\mathrm{O}^{+}$-rich warm plasma cloak intervals are all associated with geomagnetically active times. Therefore, a separate study of the effects of the warm plasma cloak on the reconnection rate was conducted using 22 of the top geomagnetic storm days in the first two dusk-todawn sweeps of the dayside magnetopause by the MMS spacecraft. This study found that, in about $25 \%$ of the magnetopause encounters, the reconnection rate was reduced by $>20 \%$ due to the presence of the warm plasma cloak at least sometime.

Quantifying this reduction experimentally at the magnetopause is very difficult. Even if there was an experimental technique available to quantify the reconnection rate with an uncertainty of $<20 \%$, the largest effects on the reconnection described above are transient. Therefore, even the overall effect on magnetospheric dynamics, e.g. delaying substorm onset, may be relatively weak.

While this new survey of geomagnetically active times attempted to maximize the estimated effect of the warm plasma cloak on reconnection, there are reasons why this study may not capture the full extent of the reduction in the reconnection rate during a geomagnetic storm. The first reason is that the MMS spacecraft may not be in the proper location to observe the maximum $\mathrm{O}^{+}$density during a storm. Often, a storm starts with a high dynamic pressure interval, like an interplanetary shock. If MMS is near the magnetopause at the start of the storm, the compression of the magnetosphere ejects the spacecraft into the solar wind upstream from the bow shock. Thus, during the beginning of the storm and the early phases of 
geomagnetic activity, the spacecraft is often not able to make observations in the magnetosphere. The peak in the $\mathrm{O}+$ density is complicated by the finite time required for $\mathrm{O}+$ to escape the high-latitude ionosphere and convect to the dayside (if the source is on the nightside). A recent study exemplifies this complicated behavior (Allen et al., 2017). Further complication exists because the location of reconnection at the magnetopause depends on the IMF clock angle.

The second reason why the full extent of the reductions in the reconnection rate may not be captured in this study is that the MMS observations occurred during the declining phase of a relatively weak solar cycle. Table 1 shows that, for the 22 strongest storms during phases $1 \mathrm{a}$ and $1 \mathrm{~b}$, the minimum Dst was $<-150 \mathrm{nT}$ for only one storm and the minimum Dst was <-100 nT for only four storms.

In conclusion, this paper describes the effect on reconnection by the warm plasma cloak during the declining phase of a relatively weak solar cycle. The effect is relatively small because geomagnetic conditions are typically quiet during the time interval that was studied. When geomagnetic conditions are more disturbed, the effect of the warm plasma cloak on reconnection is larger and more frequent. However, the degree to which reconnection is affected by the warm plasma cloak during a very intense geomagnetic storm (i.e., one where the minimum Dst is <-200 nT) is not yet quantified.

\section{Acknowledgments}

This study was facilitated by the International Space Science Institute (ISSI) through the research team studying cold plasma of ionospheric origin. The MMS mission has been a tremendous success and the many women and men that helped create this mission share in this success. All MMS data are accessible through the MMS science data center (https://lasp. colorado.edu/mms/sdc/). Solar wind data are from the Wind spacecraft and were obtained through the CDAWeb https://cdaweb.gsfc.nasa.gov/index. html/. Research at Southwest Research Institute was funded by NASA through MMS prime contract NNG04EB99C and NASA grant 80NSSC19K1107. Work at IRAP was supported by CNRS and CNES.

\section{References}

Allen, R. C., Livi, S. A., Vines, S. K., Goldstein, J., Cohen, I., Fuselier, S. A., et al. (2017). Storm time empirical model of O+ and O6+ distributions in the magnetosphere. Journal of Geophysical Research: Space Physics, 122, 8353-8374. https://doi.org/10.1002/ 2017JA024245

André, M., Li, W., Toledo-Redondo, S., Khotyaintsev, Y. V., Vaivads, A., Graham, D. B., et al. (2016). Magnetic reconnection and modification of the Hall physics due to cold ions at the magnetopause. Geophysical Research Letters, 43, 6705-6712. https://doi.org/10.1002/ 2016GL069665

Birn, J., Borovsky, J. E., \& Hesse, M. (2008). Properties of asymmetric magnetic reconnection. Physics of Plasmas, 15(3), 032101. https://doi. org/10.1063/1.2888491

Borovsky, J. E., Denton, M. H., Denton, R. E., Jordanova, V. K., \& Krall, J. (2013). Estimating the effects of ionospheric plasma on solar wind/magnetosphere coupling via mass loading of dayside reconnection: Ion-plasma-sheet oxygen, plasmaspheric drainage plumes, and the plasma cloak. Journal of Geophysical Research: Space Physics, 118, 5695-5719. https://doi.org/10.1002/jgra.50527

Cassak, P. A., \& Fuselier, S. A. (2016). Reconnection at Earth's dayside magnetopause. In W. Gonzalez \& E. Parker (Eds.), Magnetic Reconnection, Astrophysics and Space Science Library (Vol. 427, pp. 213-276). Switzerland: Springer. https://doi.org/10.1007/978-3-31926432-5

Cassak, P. A., \& Shay, M. A. (2007). Scaling of asymmetric magnetic reconnection: General theory and collisional simulations. Physics of Plasmas, 14(10), 102114. https://doi.org/10.1063/1.2795630

Chapman, S., \& Ferraro, V. C. A. (1931). A new theory of magnetic storms: Part I - The initial phase. Terr Magn Atmos Electr, 36(77-97), 1717.

Chappell, C. R., Huddleston, M. M., Moore, T. E., Giles, B. L., \& Delcourt, D. C. (2008). Observations of the warm plasma cloak and an explanation of its formation in the magnetosphere. Journal of Geophysical Research, 113, A09206. https://doi.org/10.1029/2007JA012945

Cowley, S. W. H. (1982). The causes of convection in the Earth's magnetosphere: A review of developments during the IMS. Reviews of Geophysics, 20, 531.

Dargent, J., Aunai, N., Lavraud, B., Toledo-Redondo, S., Shay, M. A., Cassak, P. A., \& Malakit, K. (2017). Kinetic simulation of asymmetric magnetic reconnection with cold ions. Journal of Geophysical Research: Space Physics, 122, 5290-5306. https://doi.org/10.1002/ 2016JA023831

Fuselier, S. A., Burch, J. L., Cassak, P. A., Goldstein, J., Gomez, R. G., Goodrich, K., et al. (2016). Magnetospheric ion influence on magnetic reconnection at the duskside magnetopause. Geophysical Research Letters, 43, 1435-1442. https://doi.org/10.1002/ 2015GL067358

Fuselier, S. A., Burch, J. L., Mukherjee, J., Genestreti, K. J., Vines, S. K., Gomez, R., et al. (2017). Magnetospheric ion influence at the dayside magnetopause. Journal of Geophysical Research: Space Physics, 122, 8617-8631. https://doi.org/10.1002/2017JA024515

Fuselier, S. A., Lewis, W. S., Schiff, C., \& Ergun, R. (2016). Magnetospheric Multiscale Science Mission Profile and Operations. Space Science Reviews, 199, 77. https://doi.org/10.1007/s11214-014-0087-X

Fuselier, S. A., Trattner, K. J., Petrinec, S. M., Denton, M. H., Toledo-Redondo, S., André, M., et al. (2019). Mass loading the Earth's dayside magnetopause boundary layer and its effect on magnetic reconnection. Geophysical Research Letters, 46, 6204-6213. https://doi.org/ 10.1029/2019GL082384

Gkioulidou, M., Ohtani, S., Ukhorskiy, A. Y., Mitchell, D. G., Takahashi, K., Spence, H. E., et al. (2019). Low-energy (<keV) O+ ion outflow directly into the inner magnetosphere: Van Allen Probes observations. Journal of Geophysical Research: Space Physics, 124, 405-419. https://doi.org/10.1029/2018JA025862

Goldstein, J., Sandel, B. R., Thomsen, M. F., \& Reiff, P. H. (2004). Simultaneous remote-sensing and in situ observations of plasmaspheric drainage plumes. Journal of Geophysical Research, 109, A03202. https://doi.org/10.1029/2003JA010281

Graham, D. B., Khotyaintsev, Y. V., Norgren, C., Vaivads, A., André, M., Toledo-Redondo, S., et al. (2017). Lower hybrid waves in the ion diffusion and magnetospheric inflow regions. Journal of Geophysical Research: Space Physics, 122, 517-533. https://doi.org/10.1002/ 2016JA023572

Kistler, L. M., Ipavich, F. M., Hamilton, D. C., Gloeckler, G., Wilken, B., Kremser, G., \& Stüdemann, W. (1989). Energy spectra of major ion species in the ring current during geomagnetic storms. Journal of Geophysical Research, 94(A4), 3579-3599. https://doi.org/10.1029/ JA094iA04p03579 
Petrinec, S. M., Burch, J. L., Fuselier, S. A., Gomez, R. G., Lewis, W., Trattner, K. J., et al. (2016). Comparison of magnetospheric multiscale ion jet signatures with prediced reconnection site locations at the magnetopause. Geophysical Research Letters, 43, 5997-6004. https:// doi.org/10.1002/2016GL069626

Russell, C. T., Anderson, B. J., Baumjohann, W., Bromund, K. R., Dearborn, D., Fischer, D., et al. (2016). The magnetospheric multiscale magnetometers. Space Science Reviews, 199(1-4), 189-256. https://doi.org/10.1007/s11214-014-0057-3

Tenfjord, P., Hesse, M., Nrogren, C., Spinnangr, S. F., \& Kolstø, H. (2019). The impact of Oxygen on the Reconnection rate. Geophysical Research Letters, 46, 6195-6203. https://doi.org/10.1029/2019GL082175

Toledo-Redondo, S., André, M., Khotyaintsev, Y. V., Vaivads, A., Walsh, A., Li, W., et al. (2016). cold ion demagnetization near the X-line of magnetic reconnection. Geophysical Research Letters, 43, 6759-6767. https://doi.org/10.1002/2016GL069877

Wang, S., Kistler, L. M., Mouikis, C. G., \& Petrinec, S. M. (2015). Dependence of the dayside magnetopause reconnection rate on loca conditions. Journal of Geophysical Research: Space Physics, 120, 6386-6408. https://doi.org/10.1002/2015JA021524

Yau, A. W., Whalen, B. A., Peterson, W. K., \& Shelley, E. G. (1984). Distribution of upflowing ionospheric ions in the high-altitude polar cap and auroral ionosphere. Journal of Geophysical Research, 89(A7), 5507. https://doi.org/10.1029/JA089iA07p05507

Young, D. T., Burch, J. L., Gomez, R. G., De Los Santos, A., Miller, G. P., Wilson, P., et al. (2014). Hot plasma composition analyzer for the magnetospheric multiscale mission. Space Science Reviews, 199(1-4), 407-470. https://doi.org/10.1007/s11214-014-0049-6 